\title{
Changes in Norisoprenoid Levels with Long-term Nitrogen Fertilisation in Different Vintages of Vitis vinifera var. Riesling Wines
}

\author{
A.W. Linsenmeier ${ }^{*}$ and O. Löhnertz ${ }^{2}$ \\ (1) Forschungsanstalt Geisenheim, Fachgebiet Mikrobiologie und Biochemie, D-65366 Geisenheim, von-Lade-Straße 1 \\ (2) Forschungsanstalt Geisenheim, Fachgebiet Bodenkunde und Pflanzenernährung, D-65366 Geisenheim, von-Lade-Straße 1
}

Submitted for publication: December 2006

Accepted for publication: April 2007

Key words: $\mathrm{N}$ fertilization; $\mathrm{C}_{13}$-norisoprenoids; TDN; vitispirane; damascenone

\begin{abstract}
$\mathrm{C}_{13}$-norisoprenoids were measured in Riesling wines produced from the 1996, 1997 and 2003 vintages within the scope of a long-term nitrogen $(\mathrm{N})$ fertilisation experiment. The wines were made from treatments of 0,60 and 150 $\mathrm{kg}$ N/ha; each treatment was repeated four times and arranged in a completely randomised design. $\mathrm{N}$ fertilisation led to lower TDN (1,1,6-trimethyl-1,2-dihydronaphthalene) concentrations, whereas the trend was for actinidol and B-damascenone to increase with increasing fertilisation and vitispirane was not affected by fertilisation. Yield, which was affected by $\mathbf{N}$ fertilisation, showed negative correlations with norisoprenoids in 1996 and 1997. Vitispirane, actinidol and TDN increased with storage time. The colder year, 1996, which had fewer sunshine hours, resulted in higher concentrations of B-damascenone and lower concentrations of the norisoprenoids vitispirane, actinidol and TDN compared with 1997.
\end{abstract}

\section{INTRODUCTION}

$\mathrm{C}_{13}$-norisoprenoid compounds are important contributors to the aroma of wines. They are generated from carotenoids such as lutein and B-carotene (Winterhalter et al., 1990; Winterhalter, 1991; Cox et al., 2005). Whereas a high number of different norisoprenoids have been found in Chardonnay wines, Riesling wines contain considerably fewer volatile $\mathrm{C}_{13^{-}}$norisoprenoids (Simpson and Miller, 1983, 1984; Marais et al., 1992a, 1992b; Sefton et al., 1993). ß-Ionone and ß-damascenone yield intense fruity flavours. On the other hand, actinidol, vitispirane and 1,1,6trimethyl-1,2-dihydronaphthalene (TDN) are significant in the ageing of wines (Simpson and Miller, 1983; Dimitriadis et al., 1998; Ferreira et al., 2003; Francioli et al., 2003). TDN is responsible for the kerosene-like note in Riesling wines, which is also called the "petrol note" (Simpson, 1978). In Riesling wine produced in cooler climatic zones, TDN can only be perceived after four to six years of bottle ageing. In hot wine-producing regions, TDN can arise much earlier and in considerably higher quantities, causing these wines to be rejected (Rapp, 2004). Grapes exposed to direct sunlight also yield wines containing higher TDN concentrations than shaded grapes (Marais et al., 1992a). Whereas the effects of different Riesling clones, yeast and vintage, as well as the wine-producing region and sunlight exposure on the generation of $\mathrm{C}_{13}$-norisoprenoids, especially TDN, are well known (Marais et al., 1992a, 1992b, 1992c; Sponholz and Hühn, 1997; Periadnadi, 2003), to our knowledge no studies have been carried out on the influence of $\mathrm{N}$ supply. This is especially true for the other norisoprenoids listed above. Since the sensorially important $\mathrm{C}_{13}$-norisoprenoid compounds in Riesling wines are especially associated with ageing, the aim of the present study was to examine the ageing process of Riesling wines produced from grapes grown at different $\mathrm{N}$ fertilisation levels.

\section{MATERIALS AND METHODS}

\section{Field experiment}

The field experiment was conducted in the Rheingau, Germany $\left(50^{\circ} \mathrm{N}, 8^{\circ} \mathrm{E}\right)$, in a vineyard of Riesling grapevines on $5 \mathrm{C}$ rootstock planted in 1977. The vines were planted in loamy sand, originating from tertiary sea sand containing $1.5 \%$ humus, the $\mathrm{pH}$ value was approximately 7.5 and the available water capacity was $28 \%$ (v/v, soil analysis details in Table 1). The vines were spaced $1.3 \mathrm{~m}$ (within rows) by $1.9 \mathrm{~m}$ (between rows), trained to one vertically positioned cane, and were pruned to $5 \mathrm{buds} / \mathrm{m}^{2}$ with a south-east aspect. There was permanent green cover in every second row. Soil management consisted of four to five times mulching in the green cover row, respectively, five times cultivation in the other row. Since 1985, the vineyard had been fertilised with different quantities of $\mathrm{N}(0,30,60,90,150 \mathrm{~kg} \mathrm{~N} /$ (ha year). The fertiliser was granular ammonium nitrate $(27.5 \% \mathrm{~N})$. Phosphorus, potassium, magnesium fertiliser addition, pest control and other vineyard operations were consistent with commercially-accepted practices. In 2003, a thinning action was carried out to improve wine quality - the crop was reduced to two grapes per spur at véraison. The $\mathrm{N}$ treatments were completely randomised, and each fertilisation treatment consisted of four replicates of 48 vines, 20 of which were designated "data" vines. Each replication was used for micro-vinification. These grapes were weighed for an estimation of yield, destemmed and crushed. The crushed grapes were pressed and allowed to settle for $24 \mathrm{~h}$. After clarification, the musts were racked and inoculated with Saccharomyces cerevisiae strain "Champagner Epernay Geisenheim". Fermentation took place in $10 \mathrm{~L}$ glass flasks. At the end of alcoholic fermentation, the wines were racked, sulphurated with $100 \mathrm{mg} \mathrm{SO}_{2} / \mathrm{L}$, filtrated and bottled. The bottled wines were stored at $14^{\circ} \mathrm{C}$. 


\section{Analysis}

Leaf samples opposite the clusters of the first bunch of all field replicates were taken at véraison. Leaf and juice samples were analysed for $\mathrm{N}$ after a Kjeldahl digestion with sulphuric acid and hydrogen peroxide (Schaller, 2000). The analysis was carried out in replicate.

The soil was sampled in the cultivated row before budbreak (winter) and at the end of bloom for the determination of $\mathrm{NO}_{3}-\mathrm{N}$. In 2006, samples were analysed for $\mathrm{pH}\left(\mathrm{CaCl}_{2}\right)$ and organic $\mathrm{C}$ (conductometric). The soil organic material was calculated from organic $\mathrm{C}$ with a factor of 1.72. All methods are as described in Schaller (2000).

Weather data were taken from the German Meteorological Service, Geisenheim, situated $5 \mathrm{~km}$ from the experimental vineyard.

$\mathrm{C}_{13}$-norisoprenoids (see Figure 1) were measured in bottle-aged wines produced from the 1996, 1997 and 2003 vintages in January 2006. An individual bottle of each field replicate was analysed in duplicate. Ten millilitres of each sample was spiked with $20 \mu \mathrm{L}$ of internal standard solution (naphthalene $24 \mathrm{mg} / \mathrm{L}$ and 2,6-dichloraniline $175 \mu \mathrm{g} / \mathrm{L}$ in ethanol). Extraction was via stir bar sorptive extraction (SBSE) with a $10 \mathrm{~mm}$ stir bar (Twister ${ }^{\circledR}$ Gerstel, Mühlheim/Ruhr, Germany), coated with a 1 $\mathrm{mm}$ layer of polydimethylsiloxane. SBSE was performed by stirring for $1 \mathrm{~h}$ in closed $12 \mathrm{~mL}$ vials containing $10 \mathrm{~mL}$ of sample and $3.5 \mathrm{~g} \mathrm{NaCl}$. Following extraction, the stir bars were placed into a thermal desorption unit (TDS 2, Gerstel) with the following temperature programme: $20^{\circ} \mathrm{C} ; 60^{\circ} \mathrm{C} / \mathrm{min}, 150^{\circ} \mathrm{C}(10 \mathrm{~min})$. Analytes were trapped in the (CIS 4, Gerstel) and released after desorption for subsequent GC/MS analysis (temperature programme: $-150^{\circ} \mathrm{C}, 12^{\circ} \mathrm{C} / \mathrm{sec}, 280^{\circ} \mathrm{C}(5 \mathrm{~min})$ ).

Capillary GC-MS identification was carried out using a HP 6890 GC and a HP-MSD system. An SPB-5 column (60 m x 320 $\mu \mathrm{m} \times 25 \mu \mathrm{m}$; Supelco) was used. Samples were injected in splitless mode and the column carrier gas was helium at a constant flow of $1.2 \mathrm{~mL} / \mathrm{min}$. The temperature program started at $40^{\circ} \mathrm{C}$, and then increased at a rate of $4^{\circ} \mathrm{C} / \mathrm{min}$ to $250^{\circ} \mathrm{C}$, finishing with a $5 \mathrm{~min}$ hold. The injector temperature was $280^{\circ} \mathrm{C}$. The interface and ion source temperatures were set at $280^{\circ} \mathrm{C}$ and $230^{\circ} \mathrm{C}$ respectively. The MS was operated in the EI mode, with electron energy at $70 \mathrm{eV}$ in the scan mode. The sampling range was from $\mathrm{m} / \mathrm{z}$ 35 to $\mathrm{m} / \mathrm{z}, 300$ at $1.4 \mathrm{scans} / \mathrm{sec}$ for eight samplings and from $\mathrm{m} / \mathrm{z}$ 35 to $\mathrm{m} / \mathrm{z} 500$ at $2.8 \mathrm{scans} / \mathrm{sec}$ for two samplings. System software control and data analysis were performed through Enhanced ChemStation Software G1701BA (Agilent Technologies Inc.).
Vitispirane, TDN and actinidol were tentatively identified by comparing their mass spectra with those in the Wiley 6n.L library database or in the literature. $\beta$-Damascenone and B-ionone were confirmed by retention time of standard substances.

SBSE-GC/MS (in the scan mode) is a useful tool for the qualitative and quantitative analysis of wine aroma compounds (Hayasaka et al., 2003). However, it is difficult to quantify compounds with a low octanol-water partition coefficient $\left(\log \mathrm{K}_{\mathrm{OW}}\right.$ $<2,5$ ), because recovery is too low for quantification of these compounds (Hoffmann et al., 2000). However, the log $\mathrm{K}_{\mathrm{Ow}}$ of all the measured $\mathrm{C}_{13}$-norisoprenoids is high enough for quantification (Table 2). $\beta$-Damascenone and $\beta$-ionone were quantified by comparing their peak area with authentic compounds, using 2,6dichloraniline as internal standard. Quantifier ions for internal standards were $\mathrm{m} / \mathrm{z} 63$ for naphthalene and $\mathrm{m} / \mathrm{z} 161$ for 2,6dichloraniline. See Table 2 for the quantifier ions for the aroma compounds. Due to the absence of commercially available pure standards of vitispirane, TDN and actinidol, the concentrations of these compounds were calculated assuming a relative response factor of 1:1 with naphthalene. Accuracy and precision were confirmed by 10 replications with one Riesling wine. All compounds showed a normal distribution. The Grubbs test for outliers and Neumann's test for trend were both negative. The quantification limits were set at a signal to noise ratio of 6:1 and the coefficients of variation $(\mathrm{CV} \%=($ standard deviation/mean $) \times 100)$ were calculated for the compounds that were studied (Table 2). Retention indices were calculated in accordance with a modified Kováts method (Rauhut, 1996).
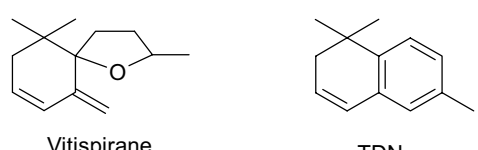

TDN

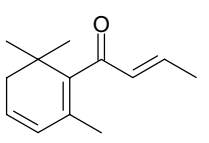

B-Damascenone

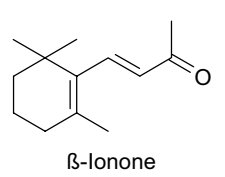

FIGURE 1
Structures of $\mathrm{C}_{13}$-norisoprenoids relevant to this work

\section{TABLE 1}

Organic material $(\mathrm{OM})$ and $\mathrm{pH}(0$ to $30 \mathrm{~cm})$ in the year 2006 and $\mathrm{NO}_{3}-\mathrm{N}$ in the soil $(0$ to $60 \mathrm{~cm})$ at bloom and in the previous winter in 1996, 1997 and 2003.

\begin{tabular}{|c|c|c|c|c|c|c|c|c|}
\hline \multirow[t]{2}{*}{ kg N/ha } & \multirow[t]{2}{*}{$\begin{array}{l}\text { OM } \\
(\%)\end{array}$} & \multirow[t]{2}{*}{$\mathbf{p H}$} & \multicolumn{2}{|c|}{$\begin{array}{c}\mathrm{NO}_{3}-\mathrm{N} 1996 \\
(\mathrm{~kg} \text { N/ha) }\end{array}$} & \multicolumn{2}{|c|}{$\begin{array}{c}\mathrm{NO}_{3}-\mathrm{N} 1997 \\
\quad(\mathrm{~kg} \text { N/ha) }\end{array}$} & \multicolumn{2}{|c|}{$\begin{array}{c}\mathrm{NO}_{3}-\mathrm{N} 2003 \\
(\mathrm{~kg} \text { N/ha) }\end{array}$} \\
\hline & & & winter & bloom & winter & bloom & winter & bloom \\
\hline 0 & $\left.1.4 \mathrm{a}^{1}\right)$ & $7.4 \mathrm{a}$ & $4 \mathrm{a}$ & $52 \mathrm{a}$ & $5 \mathrm{a}$ & $19 a$ & $5 \mathrm{a}$ & $32 \mathrm{a}$ \\
\hline 60 & $1.5 \mathrm{a}$ & $7.5 \mathrm{a}$ & $9 \mathrm{~b}$ & $61 \mathrm{a}$ & $11 \mathrm{~b}$ & $24 \mathrm{a}$ & $11 \mathrm{a}$ & $57 \mathrm{a}$ \\
\hline 150 & $1.5 \mathrm{a}$ & $7.5 \mathrm{a}$ & $18 \mathrm{c}$ & $184 \mathrm{~b}$ & $21 \mathrm{c}$ & $80 \mathrm{~b}$ & $28 \mathrm{~b}$ & $117 \mathrm{~b}$ \\
\hline
\end{tabular}

1) Significant differences between treatments are indicated by different letters $(\alpha=0.1 \%)$. 


\section{Statistical analysis}

The data from the duplicated analysis were combined for further statistical analysis. To calculate the significance of means of the four field replicates, an ANOVA was carried out using Fischer's test. A two-way ANOVA was carried out with all the data. Significant differences between the $\mathrm{N}$ treatments in the vintages were tested with a one-way ANOVA. The portion of variance was calculated by dividing the sum of squares of the effect by the total sum of the squares. Principal component analysis was carried with all vintages together and individually. Bartlett's sphericity test showed that, at the level of significance $\alpha=0.05$, the correlation between variables was significant.

\section{RESULTS}

\section{Grapevine performance}

The unfertilised vines differed from the other treatments visually, i.e. in growth, foliage surface and colour of the leaves. On average, pruning mass was reduced by $25 \%$ and area per leaf by $18 \%$ in the unfertilised control compared to the $\mathrm{N}$ treatments (Linsenmeier et al., 2007). In 1996 and 1997, the yield of treatments without $\mathrm{N}$ fertilisation was lower by $18 \%$. In 2003, the only year when a thinning was carried out, no significant differences were found between the means of the four replicates (Table 3). On the other hand, the fertilised treatments could not be distinguished according to pruning mass, foliage surface or yield. Moreover, titratable acid (TA) and total soluble solids (TSS) in the must were not affected by fertilisation (see Tables 3 and 4). As expected, the $\mathrm{N}$ concentration in the must showed highly significant treatment differences. Within the years, it accounted for 80 to $90 \%$ of the variance. The $\mathrm{N}$ fertilisation of the treatments led to a significantly higher $\mathrm{N}$ concentration in the must, although however the effect of the vintage was much more important than the effect of fertilisation. Regarding all vintages, fertilisation

\section{Variables (axes F1 and F2: 73 \%)}

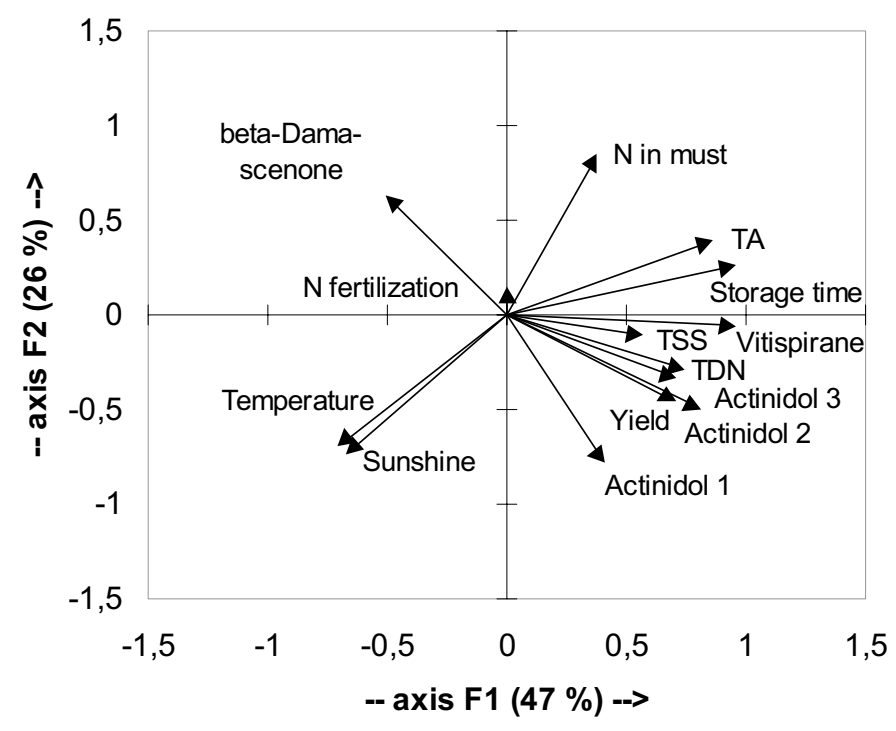

FIGURE 2

Projection of the vector loading of the norisoprenoids, the observed variables yield, total soluble solids (TSS), titratable acid (TA) and N in must, and the independent variables annual mean temperature, sum of annual sunshine hours, storage time and $\mathrm{N}$ fertilisation on principal components $\mathrm{F} 1$ and $\mathrm{F} 2$.

accounted for $13 \%$ of the variance of $\mathrm{N}$ concentration in the must, while vintage accounted for $84 \%$. In a similar way, this was true for the parameters yield, TA and TSS, which were also influenced to a highly significant extent by the vintage.

The strongest influence of $\mathrm{N}$ fertilisation was exerted on the $\mathrm{N}$ concentration in the leaves. The low content of soil organic mate-

\section{TABLE 2}

Chromatographical data of the compounds analysed: retention indices (RI), quantifier ion (QIon), quantification limit (LQ), variation of correlation $(\mathrm{CV})$, identification (ID)

\begin{tabular}{|c|c|c|c|c|c|c|c|c|}
\hline & RI & QIon & $\begin{array}{c}\mathbf{L Q} \\
(\mu \mathrm{g} / \mathrm{L})\end{array}$ & $\begin{array}{c}\mathrm{CV}(\%) \\
\mathbf{n}=\mathbf{1 0}\end{array}$ & $\log _{K_{0}}{ }^{a}$ & ID $^{b}$ & Aroma & $\begin{array}{c}\text { Flavour } \\
\text { threshold } \\
(\mu \mathrm{g} / \mathrm{L})\end{array}$ \\
\hline Vitispirane & 1281 & 192 & 1.00 & 2.8 & 4.65 & B & camphor & $800^{1)}$ \\
\hline TDN & 1352 & 157 & 0.60 & 3.7 & 5.16 & B & kerosene & $20^{2)}$ \\
\hline B-Damascenone & 1382 & 121 & 0.02 & 3.9 & 4.21 & A & rose & $50^{3)}$ \\
\hline Actinidol 1 & 1400 & 163 & 0.20 & 3.9 & 2.69 & $\mathrm{C}$ & camphor & $?^{4)}$ \\
\hline Actinidol 2 & 1427 & 163 & 0.20 & 3.5 & 2.69 & $\mathrm{C}$ & camphor & $?^{4)}$ \\
\hline Actinidol 3 & 1452 & 163 & 0.20 & 3.7 & 2.69 & $\mathrm{C}$ & camphor & $?^{4)}$ \\
\hline B-Ionone & 1482 & 177 & 0.50 & 7.5 & 4.29 & A & rose & $50^{3)}$ \\
\hline
\end{tabular}

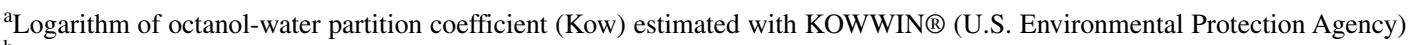

bIdentification:

A: comparison of retention time and spectra with authentic compounds

B: comparison of spectra with library matches

C: comparison of spectra with the literature

${ }^{\mathrm{c}}$ Flavour threshold in wine reported in:

1) Simpson (1979)

${ }^{2)}$ Simpson (1978)

3) Simpson and Miller (1984)

4) no threshold reported 
rial resulted in considerably lowered soil nitrate concentrations in the leaves of the unfertilised treatment. Together with lowered $\mathrm{N}$ in the must, reduced growth and lighter leaf colour, this clearly indicates a nitrogen deficiency in the unfertilised vines.

\section{Norisoprenoid concentration}

$\mathrm{N}$ fertilisation also affected TDN concentrations. Wines produced from the unfertilised treatment usually contained the highest TDN values, whereas those made from the highly fertilised treatment showed the lowest values (see Table 5). This is even true for the young vintage, 2003, whereas in 1996, this effect was not significant at $\alpha<0.1$. At the same time, an effect of the vintage can be determined (Table 6). Despite longer bottle ageing, the 1996 wines showed considerably lower concentrations compared to the 1997 vintage. The TDN concentration of the 2003 vintage was three to four times lower than in the other years.

The concentration of vitispirane measured in the wines made from the 1996 and 1997 vintages was about four times higher than in 2003. A fertilisation effect could not be detected.

Actinidol was affected by the year in a similar way as TDN. In the 1997 wines, concentrations were higher than in the 1996 wines; both were much higher than in 2003. In contrast to TDN and vitispirane, the concentrations of actinidol tended to be increased by $\mathrm{N}$ fertilisation.

The concentration of $\beta$-damascenone was highest in 2003 and 1996. The values of less than $1 \mu \mathrm{g} / \mathrm{L}$, however, were clearly below the odour threshold of $50 \mu \mathrm{g} / \mathrm{L}$ (Simpson and Miller, 1984). In 1997, the concentrations were below this threshold. N fertilisation tended to increase the concentration of $\beta$-damascenone in the wine.
In all the samples, the concentration of $\beta$-ionone in the Riesling wines was below the detection limit.

\section{Principal component analysis}

All norisoprenoids were significantly intercorrelated. As is suggested by the small angle between the vectors of TDN, vitispirane and the actinidols, these components were positively correlated (see Figure 2). In contrast, damascenone was negatively correlated to the other measured norisoprenoids. The first principal component $\mathrm{F} 1$ accounted for $47 \%$ of the variance. It was correlated to the independent variable "storage time" and to all dependent variables except actinidol 2 and $ß$-damascenone. Regarding the independent variables, the second principal component corresponded best to the weather parameters "temperature" and "sunshine". This second factor explains $25 \%$ of the overall variance. Norisoprenoids are less correlated with this axis. $\mathrm{N}$ fertilisation, represented by a small vector, was not explained by principal component analysis.

Regarding the vintages individually, in general more than one parameter could be correlated with the norisoprenoids (see Table 7). For example, in 1996, TDN was significantly correlated with yield, TSS and TA, and in 1997 with yield and N content in the must. The parameters yield, TSS, TA and $\mathrm{N}$ in the must did not affect the norisoprenoids in the same way in the different vintages: yield was negatively correlated with actinidol 1 in 1996, but significantly positive in 2003. Correlations between TSS and vitispirane or actinidol 2 and 3 respectively were positive in 1996, not significant in 1997 and significantly negative in 2003.

Considering all the vintages, the correlation between the dependent variable "yield" and all the norisoprenoids was highly sig-

\section{TABLE 3}

$\mathrm{N}$ in leaves at véraison (\% $\mathrm{N}$ in dry matter), yield ( $\mathrm{kg} / \mathrm{vine})$ and must content of total soluble solid (TSS in $\left.{ }^{\circ} \mathrm{Brix}\right)$, titratable acid (TA in $\mathrm{g} / \mathrm{L})$ and $\mathrm{N}(\mathrm{mg} / \mathrm{L})$ in the $\mathrm{N}$ treatments $(0,60$ and $150 \mathrm{~kg} \mathrm{~N} / \mathrm{ha})$ and in the mean of the vintage (in bold) \pm standard error.

\begin{tabular}{|c|c|c|c|c|}
\hline & & 1996 & 1997 & 2003 \\
\hline \multirow[t]{4}{*}{$\mathrm{N}$ in leaves } & $0 \mathrm{~kg} \mathrm{~N} / \mathrm{ha}$ & $1.81 \pm 0.07 \mathrm{a}^{1)}$ & $1.79 \pm 0.07 \mathrm{a}$ & $1.94 \pm 0.08 \mathrm{a}$ \\
\hline & $60 \mathrm{~kg} \mathrm{~N} / \mathrm{ha}$ & $2.24 \pm 0.08 \mathrm{~b}$ & $2,03 \pm 0.04 \mathrm{~b}$ & $2.13 \pm 0.03 b$ \\
\hline & $150 \mathrm{~kg} \mathrm{~N} / \mathrm{ha}$ & $2.44 \pm 0.04 \mathrm{c}$ & $2.31 \pm 0.03 \mathrm{c}$ & $2.38 \pm 0.05 \mathrm{c}$ \\
\hline & mean & $2.16 \pm 0.19 B^{1)}$ & $2.04 \pm 0.15 A$ & $2.16 \pm 0.13 B$ \\
\hline \multirow[t]{4}{*}{ Yield } & $0 \mathrm{~kg} \mathrm{~N} / \mathrm{ha}$ & $1.84 \pm 0.08 \mathrm{a}$ & $2.96 \pm 0.09 a$ & $1.55 \pm 0.13 \mathrm{a}$ \\
\hline & $60 \mathrm{~kg} \mathrm{~N} / \mathrm{ha}$ & $2.26 \pm 0.13 b$ & $3.63 \pm 0.18 b$ & $1.47 \pm 0.17 \mathrm{a}$ \\
\hline & $150 \mathrm{~kg} \mathrm{~N} / \mathrm{ha}$ & $2.21 \pm 0.19 \mathrm{~b}$ & $3.60 \pm 0.19 b$ & $1.36 \pm 0.15 \mathrm{a}$ \\
\hline & mean & $2.10 \pm 0.18 B$ & $3.39 \pm 0.19 \mathrm{C}$ & $1.46 \pm 0.17 \mathrm{~A}$ \\
\hline \multirow[t]{4}{*}{ TSS } & $0 \mathrm{~kg} \mathrm{~N} / \mathrm{ha}$ & $21.1 \pm 0.5 \mathrm{a}$ & $21.7 \pm 0.2 \mathrm{a}$ & $20.8 \pm 0.3 \mathrm{a}$ \\
\hline & $60 \mathrm{~kg} \mathrm{~N} / \mathrm{ha}$ & $21.2 \pm 0.3 \mathrm{a}$ & $21.5 \pm 0.1 \mathrm{a}$ & $20.1 \pm 0.2 \mathrm{a}$ \\
\hline & $150 \mathrm{~kg} \mathrm{~N} / \mathrm{ha}$ & $21.0 \pm 0.2 \mathrm{a}$ & $21.0 \pm 0.5 \mathrm{a}$ & $20.5 \pm 0.5 \mathrm{a}$ \\
\hline & mean & $21.1 \pm 0.2 \mathrm{~B}$ & $21.4 \pm 0.2 \mathrm{~B}$ & $20.5 \pm 0.2 A$ \\
\hline \multirow[t]{4}{*}{ TA } & $0 \mathrm{~kg} \mathrm{~N} / \mathrm{ha}$ & $12.3 \pm 0.5 \mathrm{a}$ & $10.5 \pm 0.4 \mathrm{a}$ & $6.6 \pm 0.2 \mathrm{a}$ \\
\hline & $60 \mathrm{~kg} \mathrm{~N} / \mathrm{ha}$ & $11.8 \pm 0.2 \mathrm{a}$ & $10.7 \pm 0.2 \mathrm{a}$ & $6.8 \pm 0.1 \mathrm{a}$ \\
\hline & $150 \mathrm{~kg} \mathrm{~N} / \mathrm{ha}$ & $11.9 \pm 0.2 \mathrm{a}$ & $10.4 \pm 0.4 \mathrm{a}$ & $6.7 \pm 0.2 \mathrm{a}$ \\
\hline & mean & $12.0 \pm 0.2 \mathrm{C}$ & $10.5 \pm 0.1 \mathrm{~B}$ & $6.7 \pm 0.1 A$ \\
\hline \multirow[t]{4}{*}{$\mathrm{N}$ in must } & $0 \mathrm{~kg} \mathrm{~N} / \mathrm{ha}$ & $616.3 \pm 35.9 \mathrm{a}$ & $145.9 \pm 6.5 \mathrm{a}$ & $171.1 \pm 20.5 \mathrm{a}$ \\
\hline & $60 \mathrm{~kg} \mathrm{~N} / \mathrm{ha}$ & $803.1 \pm 24.2 \mathrm{~b}$ & $233.8 \pm 27.2 \mathrm{~b}$ & $238.3 \pm 22.4 \mathrm{~b}$ \\
\hline & $150 \mathrm{~kg} \mathrm{~N} / \mathrm{ha}$ & $938.1 \pm 19.7 \mathrm{c}$ & $368.8 \pm 22.6 \mathrm{c}$ & $358.7 \pm 30.1 \mathrm{c}$ \\
\hline & mean & $785.8 \pm 93.5 B$ & $249.5 \pm 26.0 A$ & $256.1 \pm 13.9 \mathrm{~A}$ \\
\hline
\end{tabular}

1) Significant differences between treatments are indicated by different small letters; significant differences between the means of the years are indicated by different capital letters $(\alpha=0.1 \%)$. 
TABLE 4

Portion of variance (\%) by two-way ANOVA with the dependent variables $\mathrm{N}$ in leaves, yield, TSS (total soluble solids in must), TA (titratable acid in must) and $\mathrm{N}$ content in must, and the independent variables vintage and fertilisation.

\begin{tabular}{|c|c|c|c|c|}
\hline & Vintage (V) & Fertilisation (F) & $\mathbf{V} \times \mathbf{F}$ & Residual \\
\hline $\mathrm{N}$ in leaves & $4.6^{*}$ & $76.0 * * *$ & 3.2 & 16.1 \\
\hline Yield & $85.1 * * *$ & $2.8^{*}$ & $3.2 *$ & 8.9 \\
\hline TSS & $28.8 * *$ & 4.7 & 6.7 & 59.8 \\
\hline $\mathrm{TA}$ & $94.5 * * *$ & 0.1 & 0.3 & 5.1 \\
\hline $\mathrm{N}$ in must & $83.6^{* * *}$ & $13.2 * * *$ & $0.9 *$ & 2.4 \\
\hline
\end{tabular}

$*$, **, *** significant at $\alpha=0.1 \%, 0.01 \%, 0.001 \%$

TABLE 5

Effect of $\mathrm{N}$ fertilisation and year on $\mathrm{C}_{13}$-norisoprenoids (mean \pm standard error in $\mu \mathrm{g} / \mathrm{L}$ ). Vintages were analysed in January 2006.

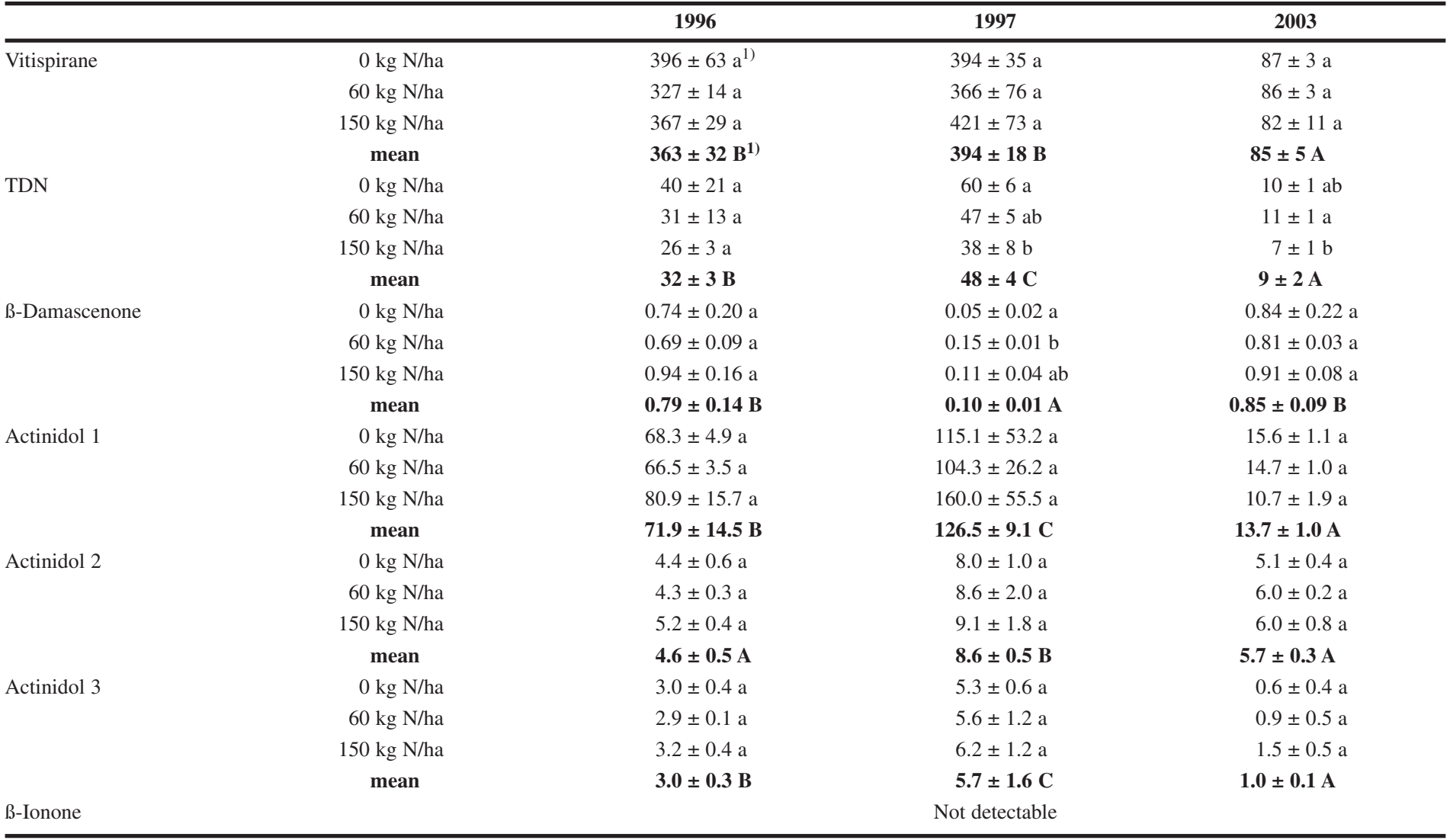

1) Significant differences between treatments are indicated by different small letters; significant differences between years are indicated by capital letters $(\alpha=0.1 \%)$.

nificant. TSS and TA showed lower correlations. Except for $ß$-damascenone, the regression coefficients of these variables were positive. The $\mathrm{N}$ content in the must only showed a reduced correlation with vitispirane, 3 -damascenone and actinidol 2, and no correlation with TDN.

\section{DISCUSSION}

Among the $\mathrm{C}_{13}$-norisoprenoids in Riesling wines, TDN is of special importance because of its contribution to the kerosene-like note. The concentration of TDN in other cultivars is too low to be perceived (Marais et al., 1992a). The sensorial threshold is reported to be $20 \mu \mathrm{g} / \mathrm{L}$ (Simpson, 1978).

In this experiment, long-term $\mathrm{N}$ deficiency in vines resulted in higher TDN concentrations in the wines (see Table 5). As TDN is formed in wines during bottle ageing, there must be an $\mathrm{N}$ effect on the precursor. Lutein is reported to be the most important precursor of TDN. Only little amounts of TDN are generated from Bcarotene (Periadnadi, 2003; Marais, 1992). Whereas Bureau et al. (1998) found higher concentrations of lutein and B-carotene in the ripe berries of shaded grapes, Steel and Keller (2000) measured 
TABLE 6

Portion of variance (\%) by two-way ANOVA with norisoprenoids as dependent variables and vintage and fertilisation as independent variables.

\begin{tabular}{|c|c|c|c|c|}
\hline & Vintage (V) & Fertilisation (F) & $\mathbf{V} \times \mathbf{F}$ & Residual \\
\hline Vitispirane & $75.7 * * *$ & 0.8 & 0.9 & 22.6 \\
\hline TDN & $47.4 * * *$ & 5.0 & 2.2 & 45.4 \\
\hline ß-Damascenone & $67.4 * * *$ & 1.5 & 1.5 & 29.5 \\
\hline Actinidol 1 & $45.8 * * *$ & 2.0 & 2.5 & 49.7 \\
\hline Actinidol 2 & $53.6 * * *$ & 1.2 & 1.1 & 44.1 \\
\hline Actinidol 3 & $74.7 * *$ & 1.1 & 0.2 & 24.1 \\
\hline
\end{tabular}

$*, * *, * * *$ significant at $\alpha=0.1 \%, 0.01 \%, 0.001 \%$

\section{TABLE 7}

Correlation matrix (R) between the dependent parameters yield, total soluble solids (TSS), titratable acid (TA), N in must and norisoprenoids within the individual vintages 1996, 1997 and $2003(\mathrm{n}=12)$ and across all vintages. Here the independent variables storage time, annual mean temperature and sum of annual sunshine hours $(\mathrm{n}=36)$ are included.

\begin{tabular}{|c|c|c|c|c|c|c|c|}
\hline & & Vitispirane & TDN & B-Damascenone & Actinidol 1 & Actinidol 2 & Actinidol 3 \\
\hline \multirow[t]{4}{*}{1996} & Yield & $-0.65 *$ & $-0.50 *$ & -0.26 & $-0.52 *$ & -0.34 & -0.39 \\
\hline & TSS & $0.74 * *$ & $0.82 * *$ & 0.14 & 0.28 & $0.55^{*}$ & $0.55^{*}$ \\
\hline & TA & $-0.70 *$ & $-0.63 *$ & -0.18 & -0.25 & $-0.79 * *$ & $-0.71 * *$ \\
\hline & $\mathrm{N}$ in must & 0.02 & -0.05 & $0.46^{*}$ & 0.32 & $0.50 *$ & 0.31 \\
\hline \multirow[t]{4}{*}{1997} & Yield & -0.10 & $-0.62 *$ & 0.14 & -0.39 & -0.15 & -0.16 \\
\hline & TSS & -0.44 & -0.07 & -0.48 & -0.01 & -0.45 & -0.43 \\
\hline & TA & -0.39 & -0.19 & $-0.51 *$ & -0.10 & -0.39 & -0.37 \\
\hline & $\mathrm{N}$ in must & 0.19 & $-0.53 *$ & 0.30 & 0.27 & 0.23 & 0.22 \\
\hline \multirow[t]{4}{*}{2003} & Yield & 0.23 & 0.06 & -0.33 & $0.55^{*}$ & 0.29 & -0.05 \\
\hline & TSS & $-0.59 *$ & -0.36 & -0.31 & -0.31 & $-0.78 * *$ & -0.16 \\
\hline & TA & 0.08 & 0.40 & -0.46 & -0.27 & -0.18 & 0.22 \\
\hline & $\mathrm{N}$ in must & $-0.52 *$ & $-0.55^{*}$ & 0.38 & $-0.60 *$ & 0.22 & 0.17 \\
\hline \multirow[t]{7}{*}{ all } & Yield & $0.61 * * *$ & $0.48 * *$ & $-0.77 * * *$ & $0.52 * *$ & $0.56^{* * * *}$ & $0.76^{* * *} *$ \\
\hline & TSS & $0.45^{* *}$ & $0.58 * * *$ & $-0.41 *$ & $0.37 *$ & 0.07 & $0.37 *$ \\
\hline & $\mathrm{TA}$ & $0.73 * * *$ & $0.44 * *$ & $-0.29^{*}$ & $0.45 * *$ & -0.03 & $0.47 * *$ \\
\hline & $\mathrm{N}$ in must & $0.34 *$ & 0.00 & $0.42 *$ & 0.06 & $-0.38 *$ & -0.06 \\
\hline & Storage time & $0.85^{* * *}$ & $0.58 * * *$ & $-0.37 *$ & $0.54 * * *$ & 0.14 & $0.62 * * *$ \\
\hline & Temperature & $-0.64 * * *$ & $-0.32 *$ & -0.05 & -0.27 & 0.24 & -0.23 \\
\hline & Sunshine & $-0.60 * * *$ & $-0.29 *$ & -0.09 & -0.23 & $0.28 *$ & -0.18 \\
\hline
\end{tabular}

*,**,**: significant values of $\mathrm{R}$ at the level of significance $\alpha=0.1 \%, 0.01 \%, 0.001 \%$

lower concentrations at decreasing UV radiation. Schultz et al. (1998) found reduced concentrations of total carotenoids in Riesling grapes (at harvest) caused by higher UV-B levels.

Due to the larger leaf area of the fertilised treatments, a shading effect could be expected. Thus, a secondary $\mathrm{N}$ fertilisation effect due to the increased sun exposure of the $\mathrm{N}$ stress treatment might be possible. An increase in carotenoids, which serve as protection against more intense UV radiation, might be the result. According to Marais et al. (1992a), more sun exposure results in an increase in the concentration of potential TDN.
In addition, nitrogen deficiency led to smaller berries with reduced yield (see Table 3). As carotenoids are located in the skins (Razungles et al., 1998), this could also explain the decrease of TDN with $\mathrm{N}$ fertilisation. In fact, yield was negatively correlated with norisoprenoids in 1996 (and with TDN in 1997). The positive correlation in 2003 can be explained by the thinning that was carried out in this vintage, which led to the highest yield in the unfertilised treatment. Still, following these arguments, yield should also affect the other norisoprenoids, but this could not be observed in the present trial. 
TABLE 8

Sum of sunshine hours, mean temperature in 1996, 1997 and 2003, and means of 30 years (1971-2000) (data from the German Meteorological Service, Geisenheim).

\begin{tabular}{|c|c|c|c|c|c|}
\hline & & 1996 & 1997 & 2003 & mean \\
\hline \multirow[t]{3}{*}{ Temperature (average, ${ }^{\circ} \mathrm{C}$ ) } & annual & 9.2 & 10.5 & 11.2 & 10.2 \\
\hline & growing season (Apr-Oct) & 14.3 & 15.0 & 16.3 & 14.7 \\
\hline & ripeness (July-Sept) & 16.6 & 18.5 & 19.7 & 17.5 \\
\hline \multirow[t]{3}{*}{ Sunshine (sum, h) } & annual & 1565 & 1787 & 2190 & 1603 \\
\hline & growing season (Apr-Oct) & 1234 & 1446 & 1641 & 1272 \\
\hline & ripeness (July-Sept) & 561 & 713 & 789 & 597 \\
\hline
\end{tabular}

An increase in acid-released TDN concentration is reported with an increase in ripeness (Marais et al., 1992a; Strauss et al., 1987). More mature grapes show a higher content of TSS and a lower content of TA. In this experiment, no fertilisation effect on TSS and TA could be found in the must (see Table 3 ). The correlations between these parameters and norisoprenoids were not consistent in the different vintages (see Table 7). TDN, for example, correlated negatively with TSS in 2003 but positively in 1996. Therefore it is unlikely that the significantly positive correlation across all vintages is due to ripeness.

To our knowledge, no studies have been carried out on the effect of $\mathrm{N}$ fertilisation on carotenoids in grapes. Fertilisation increases the concentration of carotenoids in vine leaves (Chen and Cheng, 2003) - this should be expected for grapes as well. Still, a higher carotenoid content in grapes would contradict the results mentioned above. This might be the reason for the differences between the response of TDN to $\mathrm{N}$ fertilisation and the reactions of the two other ageing compounds vitispirane and actinidol: actinidol tended to increase with $\mathrm{N}$ fertilisation, whereas vitispirane did not react to $\mathrm{N}$ supply in the present trial. According to Marais et al. (1992a), however, the concentrations of actinidol and vitispirane are also lower due to the shading of the grapes. The trend was for the concentrations of $\beta$-damascenone in wine to be higher due to $\mathrm{N}$ fertilisation. This matches the observation that the concentration of $\beta$-damascenone is not (significantly) lowered in shaded grapes and their wines (Marais et al., 1992a).

Nitrogen fertilisation enhances carotenoid synthesis (Chen and Cheng, 2003), but carotenoids can be reduced if the grapes are shaded (Steel and Keller, 2000). Both mechanisms might affect each specific norisoprenoid in a different way, because they have various precursors that differ in their reaction to stress: lutein increases, but the total carotenoids decrease due to higher levels of UV radiation (Bureau et al., 1998, Schultz et al., 1998). The mechanism of the effect of $\mathrm{N}$ fertilisation on $\mathrm{C}_{13}$-norisoprenoids in wines could not be fully elucidated. The secondary effects of $\mathrm{N}$ deficiency might act diametrically to the fertilisation effects on the precursor lutein and other carotenoids. Our knowledge about the influence of $\mathrm{N}$ fertilisation on the precursors of norisoprenoids in grapes is still rather limited.

The influence of the vintages on the concentrations of norisoprenoids was highly significant (see Table 6). It is not possible to attribute this effect to one cause, because the variable "vintage" in reality represents an inseparable mix of variables: not only weather conditions and storage time, but even yield, TSS, TA and $\mathrm{N}$ supply can be regarded as being part of the variable "vintage".

As expected, the concentrations of TDN and the other ageing compounds increased with bottle ageing, while $B$-damascenone decreased with bottle-ageing (see Table 5 and Figure 2). Statistically, this effect of the vintage could even be explained by yield, TSS or TA. Considering that the correlation between these parameters and the norisoprenoids was reverse or not very close within the different vintages, it must be assumed that yield, TSS and TA did not affect the different norisoprenoid concentrations. The lowered concentrations of the ageing compounds vitispirane, TDN and actinidol in the 1996 vintage, which was stored longer compared to the 1997 vintage, cannot be explained by differences in yield, but by the higher temperature and number of sunshine hours in 1997 (see Table 8). This matches the observations of Marais et al. (1992a, 1992b) that higher temperature and more sunshine hours lead to higher concentrations of TDN, vitispirane and actinidol.

\section{CONCLUSION}

In the current investigation, TDN decreased with $\mathrm{N}$ fertilisation. This result was not influenced by the storage time of the wines. In this long-term experiment, secondary effects of fertilisation are possible due to differences in foliage surface and pulp to skin ratio. Further experiments therefore should be carried out to investigate the direct impact of $\mathrm{N}$ supply on TDN formation.

On the other hand, B-damascenone, as a positive aroma compound, showed a tendency to decrease with $\mathrm{N}$ deficiency. As in this experiment (and also in general), the $B$-damascenone concentration in Riesling wines is clearly below the flavour threshold, and the observed differences are not sensorially significant. However, it can be assumed that $\mathrm{N}$ fertilisation has an influence on the aroma profile of other varieties.

\section{LITERATURE CITED}

Bureau, S.M., Razungles, A.J., Raymond, L.B. \& Bayonove, C.L., 1998. Effect of vine or bunch shading on the carotenoid composition on Vitis vinifera L. berries. II. Muscat of Frontignan grapes. Vitic. Enol. Sci. 53, 72-78.

Chen, L.-S. \& Cheng, L., 2003. Both xanthophyll cycle-dependent thermal dissipation and the antioxidant system are up-regulated in grape (Vitis vinifera L. cv. Concord) leaves in response to $\mathrm{N}$ limitation. J. Exp. Bot. 54, 2165-2175.

Cox, A., Capaone, D.L., Elsey, G.M., Perkins, M.V. \& Sefton, M.A., 2005. Quantitative analysis, occurrence, and stability of (E)-1-(2, 3, 6trimethylphenyl)buta-1, 3-diene in wine. J. Agric. Food Chem. 53, 3584-3591. 
Dimitriadis, E., Strauss, C.R., Wilson, B. \& Williams, P.J., 1998. The actinidols: Nor-isoprenoid compounds in grapes, wines and spirits. Phytochem. 24, 767-770.

Ferreira, A.C.S., Hogg, T. \& De Phino, P.G., 2003. Identification of key odorants related to the typical aroma of oxidation-spoiled white wines. J. Agric. Food Chem. 51, 1377-1381.

Francioli, S., Torrens, J., Riu-Aumatell, M., López -Tamanes, E. \& Buxaders, S., 2003. Volatile compounds by SPME-GC as age markers of sparkling wines. Am. J. Enol. Vitic. 54, 158-162.

Hayasaka, Y., MacNamara, K., Baldock, G.A., Taylor, R.L. \& Pollnitz, A.P., 2003. Application of stir bar sorptive extraction for wine analysis. Anal. Bioannal. Chem. 375, 948-955.

Hoffmann, A., Sponholz, W.R., David, F. \& Sandra, P., 2000. Corkiness in wine trace analysis of 2,4,6-trichloranisole by stir bar sorptive extraction (SBSE) and thermal desorption GC/MS. Gerstel AppNote 3/2000.

Linsenmeier, A., Rauhut, D., Kürbel, H., Schubert, S. \& Löhnertz, O., 2007. Ambivalence of the influence of nitrogen supply on o-aminoacetophenone in 'Riesling' wine. Vitis 46, 91-97.

Marais, J., 1992. 1,1,6-Trimethyl-1,2-dihydronaphthalene (TDN): A possible degradation product of lutein and beta-carotene. S. Afr. J. Enol. Vitic. 13, 52-55.

Marais, J., Van Wyk, C.J. \& Rapp, A., 1992a. Effect of sunlight and shade on norisoprenoid levels in maturing Weisser Riesling and Chenin blanc grapes and Weisser Riesling wines. S. Afr. J. Enol. Vitic. 13, 23-32.

Marais, J., Van Wyk, C.J. \& Rapp, A., 1992b. Effect of storage time, temperature and region on the levels of 1,1,6-trimethyl-1,2-dihydronaphthalene and other volatiles, and on quality of Weisser Riesling wines. S. Afr. J. Enol. Vitic. 13, 33-44.

Marais, J., Versini, G., Van Wyk, C.J. \& Rapp, A., 1992c. Effect of region on free and bound monoterpene and $\mathrm{C}_{13}$-norisoprenoid concentrations in Weisser Riesling wines. S. Afr. J. Enol. Vitic. 13, 71-77.

Periadnadi, N., 2003. Das Vorkommen der die Alterung auslösenden Precursoren und der Einfluss von Mikroorganismen auf die TDN-Bildung in Wein. Thesis, Johann Wolfgang Goethe-Universität, Frankfurt (Main), Germany.

Rapp, A., 2004. Einfluss von Standortfaktoren und Klima auf charakteristische Aromastoffe des Weines und deren Veränderung während der Alterung. In: Proc. Geisenheimer Betriebsleitertagung. pp. $10-12$.

Rauhut, D., 1996. Qualitätsmindernde schwefelhaltige Stoffe im Wein Vorkommen, Bildung, Beseitigung. Thesis, Justus-Liebig-Universität Gießen, Germany, Geisenheimer Berichte Bd. 24.
Razungles, A., Bayonove, C.L., Cordonnier, R.E. \& Sapis, J.C., 1998. Grape carotenoids: Changes during the maturation period and localization in mature berries. Am. J. Enol. Vitic. 39, 44-48.

Schaller, K., 2000. Praktikum zur Bodenkunde und Pflanzenernährung. Geisenheimer Berichte Bd. 2.

Schultz, H.R., Löhnertz, O., Bettner, W., Balo, B., Linsenmeier, A., Jähnisch, M., Müller, B., Gaubatz, B. \& Varadi, G., 1998. Is grape composition affected by current levels of UV-B radiation? Vitis 37, 191-192.

Sefton, M.A., Francis, I.L. \& Williams, P.J., 1993. The volatile composition of chardonnay juices: A study by flavor precursors analysis. Am. J. Enol. Vitic. 44, 359-370.

Simpson, R.F., 1978. 1,1,6-Trimethyl-1,2-dihydronaphthalene: an important contributor to the bottle aged bouquet of wine. Chem. Ind. 1, 37.

Simpson, R.F., 1979. Aroma composition of bottle aged white wine. Vitis 18, 148154

Simpson, R.F. \& Miller, G.C., 1983. Aroma composition of aged Riesling wine. Vitis 22, 51-63.

Simpson, R.F. \& Miller, G.C., 1984. Aroma composition of Chardonnay wine. Vitis 23, 143-158.

Sponholz, W.-R. \& Hühn, T., 1997. Einflußfaktoren von Klonenmaterial und verwendetem Hefestamm auf die Alterung von Riesling Weinen. Vitic. Enol. Sci. 52, 103-108

Steel, C.C. \& Keller, M., 2000. Influence of UV-B irradiation on the carotenoid content of Vitis vinifera tissues. Biochemical Society Transaction 28, 883-885.

Strauss, C.R., Wilson, B., Anderson, R. \& Williams, P.J., 1987. Development of precursors of $\mathrm{C}_{13}$-norisoprenoid flavorants in Riesling grapes. Am. J. Enol. Vitic. $38,23-27$.

Winterhalter, P., 1991. 1, 1, 6-Trimethyl-1, 2-dihydronaphthalene (TDN) formation in wine. 1. Studies on the hydrolysis of 2, 6, 10, 10-tetramethyl-1-oxaspiro[4.5]de-6-ene-2, 8-diol rationalizing the origin of TDN and related $\mathrm{C}_{13}$ norisoprenoids in Riesling wine. J. Agric. Food Chem. 39, 1825-1829.

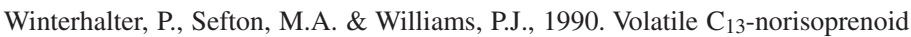
compounds in Riesling wine are generated from multiple precursors. Am. J. Enol. Vitic. 41, 277-283. 